\title{
Meal-size effects on schedule-induced ethanol and water consumption
}

\author{
R. M. GILBERT \\ Addiction Research Foundation, Toronto, Canada M5S 2S1
}

Food-deprived rats were given an unpredictable number of 45 -mg pellets every 90 sec during daily 2 -h sessions. Fluid was available for $15 \mathrm{sec}$ in the middle of each 90 -sec interval: For two rats the fluid was water, for two rats it was $5 \%$ ethanol, and for two rats it was $10 \%$ ethanol. When one or five pellets were being presented, the proportion of all drinking occurring in intervals following the larger meal increased with ethanol concentration. When zero or one pellet was being presented the proportion following the larger meal declined with ethanol concentration. When one or five pellets were delivered, the differences in proportion largely reflected differences in the number of intervals in which drinking occurred, but when zero or one pellet was delivered, the differences in proportion were due mainly to differences in the amount drunk per interval. The role of meal size in schedule-induced polydipsia remains puzzling.

Food-deprived rats drink a surprisingly large amount of water when they are fed small meals of food at infrequent intervals, a phenomenon that is known as schedule-induced polydipsia (see Falk, 1972, for a review). Ethanol solutions are also drunk to excess when small amounts of food are presented intermittently, although some details of the phenomenon vary according to concentration (Gilbert, in press). Many authors have argued that ethanol's calorific value is a major determinant of ethanol drinking under such conditions (e.g., Lester \& Freed, 1972). If calories are an important feature of alcohol consumption, one would expect the amount of alcohol consumed to vary inversely with the amount of food consumed, other things being equal.

The present study is concerned with the variation in ethanol consumption during intermittent feeding as a function of the number of food pellets presented during the previous meal. In the first part of the study, one or five pellets were presented unpredictably at the end of each 90-sec interval; in the second part, zero or one pellet was so presented. If ethanol is being drunk because it is a food, one might suppose that less drinking would occur during intervals that followed delivery of the larger meal in each case.

No previous studies have examined ethanol drinking as a function of meal size. In the case of water, the relation between amount drunk and number of pellets per meal is controversial: Some authors have reported a decline in drinking with increasing numbers of pellets (e.g., Falk, 1967) and some have reported an increase (e.g., Couch, 1974). The various studies are difficult to compare, however, because

Marilyn Schwieder and William Thomas provided valuable assistance during the conduct of this study. Reprints are available from the author at 33 Russell Street, Toronto, Canada M5S 2S1. interval length was sometimes varied at the same time as meal size and because the time taken to eat the pellets was sometimes not taken into account. Where zero or one pellet has been presented, however, as in second-order schedules, there is general unanimity that more drinking occurs after pellet deliveries (Allen, Porter, \& Arazie, 1975).

The present study examined both ethanol and water drinking as a function of meal size. The interval length was kept constant by presenting food independently of the rats' behavior. Fluid was available only in the middle of each 90 -sec interval in order to separate drinking from eating. [An earlier study had shown that such a procedure induces drinking of both water and ethanol solutions (Gilbert, 1974)]. Additionally, the present procedures varied the number of pellets per interval within each experimental session, thus providing a more local comparison of the effect of meal size on drinking than previous studies, in which variation in meal size occurred between sessions only. In this way, too, food was presented at the same overall rate in each session, thus avoiding the possibility that drinking might vary as a function of the general rate of ingestion of food.

\section{METHOD}

\section{Subjects}

The subjects were six male hooded rats maintained at approximately $85 \%$ of their respective weights soon after their arrival from Canadian Breeding Farms, when they were aged close to 120 days and weighed close to $350 \mathrm{~g}$. Water was always available in home cages. Food was provided in controlled portions shortly after experimental sessions, or at a similar time on days during which no session was conducted. The six animals comprised three groups of two each, each group having a different fluid available during experimental sessions. One pair had water available, one pair had a $5 \%(\mathrm{w} / \mathrm{v})$ ethanol solution, and the third pair had a $10 \%(w / v)$ ethanol solution. 


\section{Procedures}

Two identical standard operant conditioning chambers were used, each equipped with a pellet dispenser and a retractable drinking tube described earlier (Gilbert, 1974). Two-hour sessions were conducted 4 or 5 days a week. The schedule of experimental sessions was such that a given subject's session occurred at approximately the same time each day; however, the two members of each group were run at different times of the day in order to avoid confusion of ethanol concentration and possible diurnal variation effects.

Subjects experienced the same sequence of experimental sessions. The sessions varied only in the number and pattern of presentation of $45-\mathrm{mg}$ Noyes food pellets. Initially, 80 pellets were presented at the beginning of each session for 12 sessions. Then one pellet was presented every $90 \mathrm{sec}$ during 30 sessions. Then one or five pellets were presented at the end of each 90 -sec interval during 42 sessions. Finally, zero or one pellet was presented at the end of each interval during a further 42 sessions. (Rats were uninformed of the end of intervals that terminated without a pellet.) The drinking tube was available only during the third or the fourth $15 \mathrm{sec}$ of each interval. There were equal numbers of each kind of interval during a session, the irregular sequence being controlled by a coded paper tape. The same sequence was used for all animals for almost all sessions: Occasionally complementary sequences were substituted to guard against the possibility of order effects.

\section{RESULTS AND DISCUSSION}

Data are presented from the final six sessions of each of the last two phases, in which one or five pellets were presented and in which zero or one pellet was presented. Rats given the same fluid differed little from each other and their data are combined. Drinking was evenly distributed between the third and fourth 15 -sec portions of the intervals; these data are also combined. An earlier study had found no systematic difference between drinking during any of the parts of a 60 -sec interval except the first (Gilbert, 1974). Lack of a difference here suggests that eating was not encroaching upon the time available for drinking, even when a meal consisted of five pellets.

Mean fluid consumption per session is indicated in the lower panel of Figure 1. The amounts may be considered polydipsic in the sense that without the intermittent feeding no animal drank more than $5 \mathrm{ml}$ during a session. The decline in water consumption from the one-or-five to the zero-or-one condition was probably caused by the change in pattern of food presentation, because it was evident as soon as the pattern was changed. The relative stability of ethanolsolution consumption across conditions is consistent with other data that point to such stability (Gilbert, in press). However, because six times as many pellets were delivered and eaten under the one-or-five condition as under the zero-or-one condition, it would have been reasonable to expect a decline in ethanol consumption from the first to the second condition, if ethanol was being ingested on account of its food value.

The upper panel of Figure 1 shows the proportion of drinking that occurred during intervals following
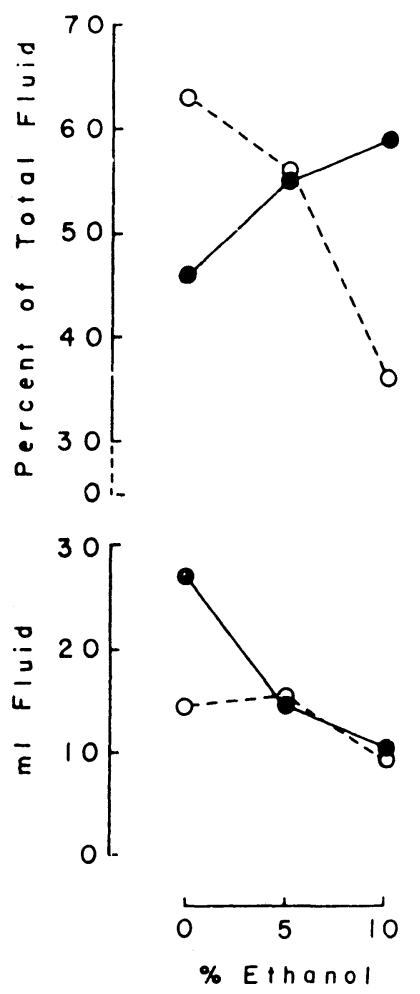

Figure 1. Shows mean fluid consumption per 2-h session (lower panel) and the proportion of fluid drunk in intervals that followed delivery of the larger number of pellets (upper panel). Each point is based on data from two rats collected during six consecutive sessions. The filled points refer to sessions in which presentation of one or five pellets terminated each interval. The open points refer to sessions in which zero or one pellet was delivered.

delivery of the larger meal. When one or five pellets were being delivered, the proportion drunk after five pellets increased with ethanol concentration. If ethanol was being drunk on account of its food value, the opposite relationship would be expected. The opposite relationship is evident in connection with the zero-orone pellet condition: The proportion of fluid drunk following delivery of one pellet declined with ethanol concentration.

The number of intervals in which drinking occurred varied in much the same way as the volume consumed, as did the proportion of such intervals following delivery of the larger meal: Thus, a figure representing intervals in which drinking occurred as a function of ethanol concentration would resemble Figure 1. However, as Figure 2 shows, fluid consumption per interval was constant only for the one-or-five condition. When zero or one pellet was presented, rats drank more water after one pellet but more $10 \%$ ethanol after zero pellets. This difference in consumption per interval accounts for most of the negative slope of the zeroor-one line in the upper panel of Figure 1. Thus the increase with ethanol concentration in the proportion of fluid consumed after five pellets in the one-or-five 


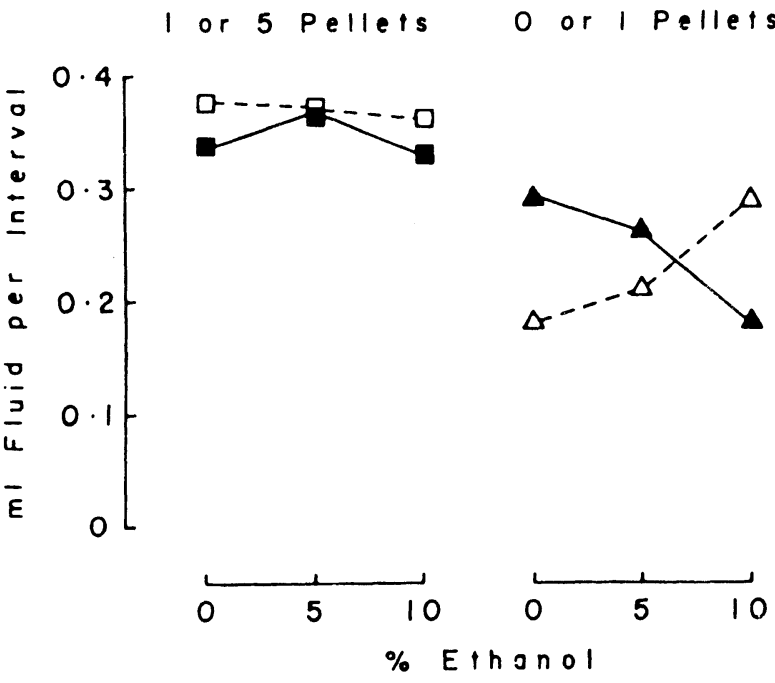

Figure 2. Shows how the fluid consumption per interval in which drinking occurred varied differently with ethanol concentration when zero or one pellet was presented but varied hardly at all when one or five pellets were presented. The open and closed triangles show mean volumes per interval that followed the delivery of zero and one pellet, respectively: The open and closed squares show volumes per interval that followed one and five pellets, respectively. Each point is based on data from two rats in six consecutive sessions.

condition occurred mainly because of variation in the number of intervals during which drinking occurred. The decline with ethanol concentration in the proportion of fluid consumed after one pellet in the zeroor-one condition occurred mainly because of changes in the volume of fluid consumed during the different kinds of interval.

Why did the likelihood of drinking after five rather than after one pellet increase with ethanol concentration? One possibility is that more was drunk after five pellets because the rats' mouths were drier, but that the difference between drinking after one and five pellets was not evident with water because drinking occurred during almost every interval. If this post hoc explanation has some validity, it implies that a dry mouth may be a more important determinant of ethanol drinking than food deprivation. However, an even stronger factor must have been responsible for the overall decline in drinking with increasing ethanol concentration.

Why was there an increase in the amount drunk after zero pellets with increasing ethanol concentration but a decrease in the amount drunk after one pellet? Here it might be reasonable to invoke food deprivation, although it is not obvious why the amount of $10 \%$ ethanol drunk per interval should have been so much lower after one pellet in the zero-or-one condition than after five pellets in the one-or-five condition. The two conditions were not strictly comparable, however, because in the first pellets were being presented every $90 \mathrm{sec}$, whereas in the second the mean interval between pellet presentations was $180 \mathrm{sec}$. An alternative explanation of the changes in amount consumed might invoke the frustration of not receiving a pellet, frustration that might have encouraged ethanol drinking to a greater extent than it encouraged water drinking. Even if there was independent evidence for such a mechanism, it would still be necessary to account for the decline with increase in ethanol concentration in the amount consumed after one pellet was delivered. The present data conflict with previous work (e.g., Allen et al., 1975) in that a substantial amount of water drinking occurred during intervals that began without a pellet delivery. The other studies of drinking induced by second-order schedules all marked the end of intervals with salient stimuli, whether or not a pellet was delivered. Thus, it is possible that such stimuli suppress drinking that might otherwise occur.

Clearly, the relation between the amount of food delivered and the amount of drinking that occurs during schedule-induced polydipsia is a more complex question than hitherto supposed. Moreover, it is also likely that schedule-induced alcohol drinking is determined by many variables in addition to alcohol's calorific value.

\section{REFERENCES}

Allen, J. D., Porter, J. H., \& Arazie, R. Schedule-induced drinking as a function of percentage reinforcement. Journal of the Experimental Analysis of Behavior, 1975, 23, 223-232.

Cоuсн, J. V. Reinforcement magnitude and schedule-induced polydipsia: A re-examination. Psychological Record, 1974, 24. 559-562.

FALK, J. L. Control of schedule-induced polydipsia: Type, size, and spacing of meals. Journal of the Experimental Analysis of Behavior, 1967, 10, 199-206.

FALK, J. L. The nature and determinants of adjunctive behaviour. In R. M. Gilbert and J. D. Keehn (Eds.), Schedule effects: Drugs, drinking, and aggression. Toronto: University of Toronto Press, 1972. Pp. 148-173.

Gilbert, R. M. Schedule-induced ethanol polydipsia in rats with restricted fluid availability. Psychopharmacologia, 1974 , 38, $151-157$.

Gilbert, R. M. Schedule-induced phenomena: Drug taking as excessive behavior. In R. Stretch (Ed.), Behavioral models of drug dependence. New York: Raven Press, in press.

LESTER, D., \& FREED, E. X. Schedule-induced consumption of ethanol: Calories or chemotherapy? In $O$. Forsander and K. Eriksson (Eds.), Biological aspects of alcohol consumption. Helsinki: Finnish Foundation for Alcohol Studies, 1972. Pp. 51-57.

(Received for publication August 21, 1975.) 